\title{
A REVIEW ON ANTIBIOTICS IN AN ANIMAL FEED
}

\author{
R. Chowdhury ${ }^{1}$, M. N. Haque, K. M. S. Islam and A. B. M. Khaleduzzaman ${ }^{2}$
}

\begin{abstract}
Food safety is a term broadly applied to food quality that may adversely affect human health. There are two major areas of concern over the presence of residues of antibiotics in animal-derived foodstuffs with regard to human health. The first is allergic reaction and the second is development of antibiotic resistance in the gut bacteria of human. Antibiotic resistance in human pathogens is now a major public health issue. Some of the resistance problem can be attributed to the transfer of resistant bacteria from animals to human and the transfer of resistance genes from animal pathogens and commensal bacteria to human pathogens. Control measures include improvements in food hygiene to reduce the spread of zoonotic bacteria to human via the food chain. However, to specifically address the issue, the livestock industries and their advisors must reduce and refine the use of antibiotics in animal production and replace antibiotics with alternative disease control measures as much as possible. In addition, the medical profession must control misuse and overuse of antibiotics in hospitals and community practice.
\end{abstract}

Key words: Antibiotic, Animal feed, Public health hazard

\section{Background}

Antibiotics are very important in animal production for a number of reasons. Firstly, they are required on animal welfare grounds. Secondly, there are economic grounds: use of antibiotics at sub-therapeutic levels (growth promotants) has a role in improving growth and production, particularly where hygiene and disease control is less than optimum level. There is evidence from Europe and Scandinavia that where hygiene and disease control regimes are of a high standard there is no reduction in production if growth promotants antibiotics are not used. However, others do not agree with this view (Lawrence, 1997). Thirdly, there are public health grounds: some argue that use of antibiotics reduces excretion of zoonotic organisms such as Salmonella (Gustafson and Bowen, 1997) but others argue that in fact use of antibiotics prolongs excretion (Corpet, 1996). Fourthly, there are reports that, some of the growth promotants are effective in controlling necrotic enteritis in chickens and swine dysentery and porcine proliferative enteropathy (Taylor, 1999).

Therapeutic use of antibiotics generally involves treatment of individual or small groups of animals with higher doses of antibiotics for a relatively short period whereas prophylactic use can involve treatment of quite large groups of animals for extended

\footnotetext{
${ }^{1}$ Department of Animal Nutrition, Bangladesh Agricultural University, Mymensingh-2202, Bangladesh

2 Department of Livestock Services, Farmgate, Dhaka-1215, Bangladesh
}

(Received: August 05, 2009) 
periods of time with moderate doses of antibiotics. Growth promotant use involves use of sub-therapeutic doses of some recognized antibiotics (e.g., tylosin, avoparcin and virginiamycin) or compounds with poorly defined antibacterial activity (e.g., ionophores) for very long periods, perhaps even for the entire life of the animals.

Great attention from a public health aspect has centered on the safety of tissue residues as a result of increased use of antimicrobial drugs. Use of drugs in animal production has expanded to the degree that approximately up to $80 \%$ of all animals produced for food purposes receive medication for part or most of their lives. All antimicrobial drugs have side effects when they are exposed to human and animals with higher dose or prolonged time than recommended. These types of toxicity are elucidated by small amounts of residual antibiotics in foods. Subtherapeutic use of antibiotics induces resistance of microorganisms that cause difficulties in treatment of animal diseases and consequently incurs abuse and tissue residue of drugs.

\section{Antibiotic resistance}

Resistance to antibiotics is one of the most serious global medical problems as we enter the 21st Century. Medical authorities are already confronted with infections for which no antibiotic is effective because the causative bacteria have acquired resistance to all available antibiotic agents. One of the issues receiving close attention at the moment is the link between use of antibiotics in animals and the development of resistance in human pathogens. There is evidence that resistance in some human enteric pathogens has arisen because of transfer of resistant bacteria or resistance genes from animals to people via the food chain (Barton, 2000). Over-use and misuse of antibiotics therapeutically has driven the resistance problem in human medicine whereas it would seem that prophylactic use to some extent and growth promotant use in particular have contributed most to the emergence of resistant bacteria in animals (van den Bogaard and Stobberingh, 1999).

\section{Development and persistence of resistance}

Development and persistence of resistance is quite variable. Some organisms appear to become resistant quite readily whereas others do not. For example, resistant strains of Salmonella typhimurium emerge rapidly after exposure to antibiotics, whereas Salmonella dublin remains relatively sensitive when exposed to the same antibiotics (MAFF, 1998). Penicillin resistance became a problem in $S$. aureus shortly after it introduction, but it took more than 20 years to appear in Streptococcus pneumoniae. Resistance to fluoroquinolones in Campylobacters (Jacobs-Rcitsnia et al., 1994) and apramycin in E. coli and Salmonella (Wray et al., 1986) emerged very quickly following the introduction of these antibiotics into veterinary medicine whereas resistance to ampicillin appeared much more gradually (Linton et al., 1988). There are many reports of the persistence of tetracycline resistance long after the withdrawal of the drug (Hinton et al., 1984) whereas there is evidence that resistance to avoparcin declines quite rapidly once use of that antibiotic ceases (Bager et al., 1999). However, it has been postulated that re-exposure to previously withdrawn antibiotics will lead to a rebound effect, with very rapid re-emergence of resistance (Salyers and Amabile-Cuevas, 1997). 


\section{Antibiotic resistance in animal isolates of bacteria}

There has been little systematic study of resistance ill animal isolates of bacteria, except for salmonella and E. coll. Until 1997, the medical impact of use of antibiotics in animals on human health, there was little interest in monitoring or surveillance of antibiotic resistance in animals (WHO, 1997).

E. coli: Escherichia coli strains are Gram-negative. This bacterium may acquire resistance from the gut microflora of the food animal even if antibiotic growth-promoters were not directly targeted against the bacteria. In herds or flocks treated with tetracycline, amino glycoside and sulphonamide, widespread resistance is seen (Williams Smith, 1980). However, resistance to other antibiotics such as ampicillin and olaquindox is less widespread (Linton et al., 1988). Multiple resistances to more than one class of antibiotics appear to be the rule with animal isolates of $E$. coli.

Salmonella spp: Salmonella was the first organism to be included in surveillance and monitoring studies (CAFA, 1997). The failure to distinguish between different serovars of Salmonella enterica limits the value of these reports as some serovars such as Typhimurium are much more likely to be resistant that other serovars such as Dublin and Enteritidis PT4 (MAFF, 1998). Resistance to tetracycline, sulphonamide and streptomycin is widespread.

Campylobacter: There are few reports on antibiotic resistance in enteric campylobacter as these organisms are not pathogens in animals and human infections rarely require treatment. Erythromycin-resistant Campylobacters have often been reported, particularly Campylobacter coli (Moore et al., 1996). Aarestrup et al. (1997) found that tetracycline resistance was more common in human than pig or poultry isolates and that there was more macrolide and streptomycin resistance in isolates from pig in comparison with human and poultry isolates. Resistance to a range of antibiotics has been reported in other studies (Saenz et al., 2000).

Enterococci: Enterococci are also enteric commensal bacteria in animals. The detection of vancomycin resistant $E$. faecium in pigs and poultry fed avoparcin (Danish Veterinary Laboratory Manual, 1995) provoked much interest and debate about the role of animal use of avoparcin in the development of vancomycin resistant enterococci (VRE) in people (Jensen et al., 1998). Investigations into resistance to other antibiotics of interest in human medicine led to the discovery of resistance to virginiamycin (Hammerum et al., 1998) and avilamycin (Aarestrup, 1998). Resistance has also been reported in enterococcal isolates from animals to the macrolide-lincosamidestreptogramin group, which includes tylosin (Aarestrup and Caetensen, 1998).

Non-enteric bacteria: Antibiotic resistance is also quite common in non-enteric organisms such as respiratory tract pathogens in all livestock species (Watts et al., 1994), Staphylococci from bovine mastitis (Aarestrup and Jensen, 1998) and small animal infections (Piriz et al., 1996). 


\section{Resistance problems in human health}

Attention to possible adverse effects of using antibiotics to human health was first received worldwide coverage with the release of a report by Swann (1969). It was concluded that the probable hazard to human health was from feeding sub-therapeutic levels of antibiotics to food producing animals (as is the case with growth promotants). The committee recommended that antibiotics for growth promotant use should be restricted to compounds not used therapeutically in man or animals and which did not select for resistance to such compounds. Link between antibiotic use in animals and the development of resistance in human pathogens is described in several reports (WHO 1998; and MAFF, 1998). The majority of human antibiotic resistance problems have connection with use of antibiotics in animals with problems occurring in both hospital and community settings (Gold and Moellering, 1996). The vancomycin-resistant enterococci were readily detected in the faeces of healthy people in the community and these appear to have originated from use of avoparcin in pigs (van den Bognard and Stobberingh, 2000). Khachatourians (1998) reported that, avoparcin withdrawal has been successful in reducing vancomycin-resistant enterococci contamination in meat products. Serious and widespread community resistance problems which have developed because of over-use and misuse of antibiotics in people include penicillinresistant pncumococci and multi-resistant Mycobacterium tuberculosis.

\section{Human health concerns}

The human health concern is the risk of direct transfer of resistant human pathogens or transfer via the food chain. Antibiotic resistance genes may be transferred from animal pathogens or commensals to human pathogens (van den Bogaard and Stobberingh, 1999 and 2000). Salmonella and Campylobacter are acknowledged food borne pathogens so it is logical to assume, that antibiotic resistant strains of these organisms will also be transferred via the food chain. E. coli is an opportunist pathogen capable of infecting people via the food chain and causing enteric infections in young children and travelers as well as a range of other infections. Enteric infections with Salmonella, E. coli or Campylobacter rarely warrant antibiotic treatment and so one might argue that the problem is not nearly as important as MRSA or other major human resistance problems. Enterococci have only been thought of as food borne organisms since the discovery of VRE in pigs and poultry and there is some dispute that this spread occurs from animals to people. However, there is evidence that transfer occurs (van den Bogaard and Stobberingh, 1999, 2000) and VRE can cause serious infections in severely ill hospitalized patients, further reducing the range of therapeutic options for those patients.

There are many reports of resistant bacteria in animals and of human isolates of the same organism with similar resistance patterns (van den Bogaard et al., 1997 and Fey et al., 2000). In addition, many published studies report the finding of the same resistance genes or resistant bacteria with the same genotype (van den Bogaard and Stobberingh, 1999 and 2000). Reports on detection of resistant bacteria with the same resistance patterns and/or of the same genotype in food are also increasing (Pavia et al., 2000) and more detailed systematic investigations are now under way (Kuhn et al., 2000). Transfer of multi-resistant $S$. typhimurium has been recognized as a serious 
problem for many years. There is a direct link between infected animals and people consuming milk or other products from such animals (Wall et al., 1995). There is ample evidence for transfer of this organism via the food chain (Threlfall et al., 2000) or by direct contact (Fone and Barker, 1994).

Detection of apramycin resistance in human strains of $E$. coli or salmonella provides evidence of transfer of this type of' resistance from animals to humans as apramycin is not used in human medicine (Wray et al., 1986). Hunter et al. (1993) reported the detection of apramcyin resistance in $E$. coli isolates from a pig farmer and his pigs. Fluoroquinolone use in animals has also led to infections in people caused by resistant strains of Campylobacter (Jacobs-Rcitsma et al., 1994 and Threlfall et al., 2000). A further concern with fluoroquinolone resistance is the emergence of resistance in Salmonella or transfer of resistance from Campylobacter to Salmonella (Glynn et al., 1998). The first evidence for transfer of vancomycin resistance from Enterococci in animals to human strains of Enterococci came from observational studies (Danish Veterinary Laboratory Manual, 1995). vanA $E$ faeciurn have been found in various foods, primarily meats (van den Bogaard and Stobberingh 2000). However, vanB $E$ faecium has not been isolated from animals (Woodford, 1998) and presumably emerged as a result of misuse and overuse of vancomycin in hospitals.

Virginiamycin has been a useful growth promotant in animal husbandry for many years. In response to the increasing MRSA and VRE problems and despite knowledge that virginiamycin was widely and legitimately used in animals, a semi-synthetic inject able human product quinupristin/dalfopristin was developed. When apparent cross-resistance between virginiamycin and dalfopristin-quinupristin was described (Hammerum et al., 1998), there were calls for the banning the use of virginiamycin as a growth promotant in animals. Everninomycin, an orthosomycin, has just been withdrawn from clinical trials as a treatment for multiply-resistant Gram-positive organisms in human. It belongs to the same class of antibiotics as avilamycin which was specifically introduced into animal husbandry as there were no related human products at the time. Avilamycin-resistant enterococci are reported to have reduced sensitivity to everninomycin (Aarestrup, 1998) and avilamycin resistant enterococci are readily isolated from poultry treated with avilamycin but not from animals that live not been treated (Aarestrup et al., $2000 a, b)$.

\section{Antimicrobial drugs in Bangladesh}

Various types of antimicrobial drugs are available in the market. The livestock owners are occasionally get confused by the advertisement of the different pharmaceutical companies claiming their products as the best and there is indiscriminate use without experimental support. In Bangladesh, only a few companies mention the withdrawal period of their product in packet. Our farmers are not so much literate that they can think about the residual effect of antibiotics which have been developed due to continuous use of these antimicrobial drugs. Livestock producers in all parts of the world will increasingly face legislative and consumer pressures to reduce the use of antimicrobial drugs which are chemically related to antibiotics used to treat human disease (Table 1). 
Bang. J. Anim. Sci. 2009, 38(1\&2)

\section{Reduction of antibiotic resistance}

Reduction in antibiotic resistance problems in people could be assisted by improved onfarm management and farm disease control. Improvements in food production and food hygiene would reduce contamination of carcasses and meat with zoonotic food borne Salmonella, Campylobacter, E. coli and Enterococci. However, there will be no specific reduction in antibiotic resistance in people until there is a concerted effort in hospitals, medical practices and the community to control the misuse and overuse of antibiotic in human medicine.

Table 1. Common antimicrobial drugs using for livestock production in Bangladesh

\begin{tabular}{|c|c|c|c|}
\hline Products name & Antimicrobial agents & Products name & Antimicrobial agents \\
\hline Aliseryl ws & $\begin{array}{l}\text { Erythromycin, } \\
\text { Oxytetracyclin, } \\
\text { Streptomycin. }\end{array}$ & Doxacil-Vet powder & Doxycyclin \\
\hline Dimoxan-150 ws & Amoxylin & Salconil powder & Salinomycin \\
\hline Doxyneo ws & Doxycyclin, Neomycin & & \\
\hline Norflox-200 oral & Norfloxaci & Docolis powder & Doxycycline \\
\hline Eska-CTC powder & Chlortetracyclin & Eskamycin bolus & Oxytetracycline \\
\hline C-Flo & Ciprofloxacin & Sulfamide- 3 bolus & $\begin{array}{l}\text { Sulphadiazine, } \\
\text { Sulphadimidine, } \\
\text { Sulphapyridine }\end{array}$ \\
\hline Enro 10 & Enrofloxacin & & \\
\hline D-Vet & Doxyclin & Eskatrim bolus & Sulphadiazine \\
\hline Oxin WS & Oxytetracyclin & $\begin{array}{l}\text { Sulprim-Vet } \\
\text { Suspension }\end{array}$ & Sulphadiazine \\
\hline Navamox & Amoxicilin & $\begin{array}{l}\text { Square CTC 15\% } \\
\text { premix }\end{array}$ & Chlortetracyclin \\
\hline Esksmysin powder & Oxytetracyclin & Ciproflox & Ciprofloxacin \\
\hline \multirow[t]{2}{*}{ Eskadox powder } & Doxycyclin & G-Enro Vet & Enrofloxacin \\
\hline & & $\begin{array}{l}\text { Ganadexil } \\
\text { Enrofloxacina }\end{array}$ & Enrofloxacin \\
\hline Eskamox powder & Amoxicilin & Acimix (vet) powder & Amoxilin \\
\hline Enroflox solution & Enrofloxicin & Bactitab & Oxytetracyclin \\
\hline Ciproflox solution & Ciprofloxacin & & \\
\hline Tialin 450 powder & $\begin{array}{l}\text { Tiamulin hydrogen } \\
\text { fumarate } 45 \% \text { powder }\end{array}$ & Bactitaab powder & Oxytetracyclin \\
\hline Furoxin powder & Furazolidone $20 \%$ & Acivet-Cipro & Ciprofloxacin \\
\hline Coc-free premix & Maduramycine & Anti-dox powder & Doxycyclin \\
\hline Cotra-Vet powder & Chlortracyclin & Moxacil-Vet powder & Amoxycilin \\
\hline
\end{tabular}




\section{Replacement of antibiotics}

Many approaches for replacement of antibiotics are already available. Improvements in hygiene and herd/flock management can significantly reduce the need for antibiotics. Specific pathogen free (SPF) flocks also have much to offer, particularly where hygiene, management and disease control strategies allow preservation of the disease free status. Alternatives of antibiotics are highly demanded due to recent withdrawal of it especially in animal feed as additive in EU (Regulation 1831/2003). Many nontherapeutic alternatives, including enzymes, organic acids, probiotics, prebiotics, herbs and etheric oils and immunostimulants have made a tremendous contribution to the profitability in the intensive husbandry and providing people with safe, healthy and nutritious livestock products.

Advance Laboratories published a report of "Antimicrobial Sensitivity Test" tested for the various Broiler \& Layer Breeders as well as Commercial Layer \& Broiler Farms. Per cent of resistance of different antibiotics against various diseases of poultry in Bangladesh is presented in following Table 2.

Table 2. Per cent resistance of different antimicrobial agents

\begin{tabular}{|c|c|c|c|c|c|}
\hline $\begin{array}{l}\text { Antibiotic } \\
\text { groups }\end{array}$ & $\begin{array}{l}\text { Antimicrobial } \\
\text { agents }\end{array}$ & $\begin{array}{c}\% \text { of } \\
\text { resistance }\end{array}$ & $\begin{array}{l}\text { Antibiotic } \\
\text { groups }\end{array}$ & $\begin{array}{l}\text { Antimicrobial } \\
\text { agents }\end{array}$ & $\begin{array}{c}\text { \% of } \\
\text { resistance }\end{array}$ \\
\hline & Ampicillin & 89 & Amino- & Gentamycin & 27 \\
\hline \multirow[t]{2}{*}{ Penicilllin } & Amoxycillin & 81 & glycosides & Neomycin & 23 \\
\hline & Cloxacillin & 89 & & Amikacin & 2 \\
\hline \multirow[t]{2}{*}{ Macrolids } & Erythromycin & 100 & Tetracyclines & Doxycycline & 98 \\
\hline & Spiramycin & 52 & & Oxytetracycline & 91 \\
\hline \multirow[t]{3}{*}{ Sulfonamides } & Sulphamethoxazole & 94 & Quinolones & Ciprafloxacin & 28 \\
\hline & Co-trimoxazole & 87 & and & Enrofloxacin & 65 \\
\hline & Trimethoprim & 94 & Florquinolones & Flumequine & 84 \\
\hline Nitrofurans & Furazolidone & 66 & & Norfloxacin & 75 \\
\hline \multirow[t]{2}{*}{ Polymyxin B \& E } & Bacitracin & 96 & & Streptomycin & 85 \\
\hline & Colistin & 20 & & Pefloxacin & 83 \\
\hline \multirow[t]{2}{*}{ Cephalosporins } & Cephalexin & 37 & Others & Fosfomycin & 17 \\
\hline & & & & Florfenicol & 2 \\
\hline
\end{tabular}

Note: Isolated organisms- E.coli, Salmonella, Pasturella multocida, Staphylococcus aureus and Proteus; Method of the test- Modified Kirby-Bauer Method. Advance Laboratories, Advance Animal Science Co. Ltd., 2005.

Probiotics are living microorganism which, given to animals, assist in the establishment of an intestinal population which is beneficial to the animal and antagonistic to harmful microbes (Green and Sainbury, 2001). The use of herbs and their products for treatment of parasitic as well as infectious disease has been practiced by the people in many countries traditionally. They may be used in animal production for obtaining safe food for human consumption because they have no residual effect on human health like antibiotic. Demir et al. (2008) indicated some herbal natural feed additives such as oregano, du-sacch, quiponin, garlic and thyme as alternatives to an antibiotic growth promoter in broiler production. 
A particular scientific interest is now paid to the antimicrobial potency of short organic acids and their salts. These have been used successfully in food animals for more than 25 years, which inhibit bacterial growth in the feed and at the opening of the digestive tract. The reduction in bacterial count reduces the disease threat and has knocked on benefit of reduced mortality. Reduced bacterial numbers in the small intestine result in decreased gut wall thickness and increased villi length which will result in improved feed conversion and thus which helps compensate for the removal of antibiotic growth promoters. In poultry production, organic acids have mainly been used in order to sanities the feed considering problems with salmonella infections (Hinton et al., 2000 and Thompson and Hinton, 1997). Feed enzyme and essential oils are also used in animal production. Feed enzymes help to break down certain components of the feed, such as glucans, proteins and phytate and increase nutrient availability. Essential oils have antimicrobial activity and effective only in higher dose in poultry.

\section{Conclusion}

It is critical for the quality of human and animal life to reduce the extent of antibiotic resistance in human and animal pathogenic and commensal bacteria. This necessitates reduction and refinement of antibiotic use and replacement of antibiotics where possible. It is difficult to justify the use of compounds with antibacterial activity as growth promotants and these compounds must be reserved for treatment of infectious diseases. Thorough enforcements of drug registration, labeling, sound use of drugs, observing withdrawal times, development of rapid screening methods and live animal tests, extension of HACCP from farm to table including quality assurance programs are consistently required. Finally, medical authorities need to take action to reduce misuse and overuse of antibiotics in hospitals and the community generally and it would be advantageous to protect critical human antibiotics by not using them in veterinary practice.

\section{Acknowledgement}

The authors are gratefully acknowledged to Advance Laboratories, Advance Animal Science Co. Ltd., 2/10 (Block-B), Lalmatia, Dhaka-1207, Bangladesh for their cordial cooperation.

\section{Literature Cited}

Aarestrup, F. M. 1998. Association between decreased susceptibility to a new antibiotic for treatment of human diseases, everninomycin (SCH 27899) and resistance - to an antibiotic used for growth promotion in animals, avilamycin. Microb. Drug Resist. 4: 137-141.

Aarestrup, F. M. and Cartensen, B. 1998. Effect of tylosin used as a growth promoter on the occurrence of macrolide-resistant Enterocncci and Staphylococci in pigs. Microb. Drug Resist. 4: 307-312. 
Aarestrup, F. M. and Jensen, E. 1998. Development of penicillin resistance among Staphylococcus aureus isolated form bovine mastitis in Denmark and other countries. Microb. Drug Resist. 4: 247-256.

Aarestrup, F. M., Ageroso, Y., Gerner-Smidt, P., Madsen, M. and Jensen, L. B. 2000a. Comparison of antimicrobial resistance phenotypes and resistance genes in Enterncoccus faccalis and Enterncoccus faecium from humans in the community, broilers and pigs in Denmark. Diagn. Microbial. Infect. Dis. 37: 127-137.

Aarestrup, F. M., Kruse, H., Tast, F., Harnmerum, A. M. and Jensen, L. B. 2000b. Association between the use of antimicrobial agents for growth promotion and the occurrence of resistance among Enterococcus faecium from broilers and pigs in Denmark, Finland and Norway. Microb. Drug Resist. 6: 63-70.

Aarestrup, F. M., Nielsen, E. M., Madsen, M. and Engberg, J. 1997. Antimicrobial susceptibility patterns of thermophilic Campylobacter spp from humans, pigs, cattle and broilers in Denmark. Antimicrob. Agents Chemother. 41: 2244-2250.

Bager, F., Aarestrup, F. M., Madsen, M. and Wegener, H. C. 1999. Glycopeptide resistance in Enterococcus faecium from broilers and pigs following discontinued use of avoparcin. Microb. Drug Resist. 5: 53-56.

Barton, M. D. 2000. Antibiotic use in animal feed and its impact on human health. Nut. Res. Rev. 13: 1-22.

CAFA (Commission on Antimicrobial Feed Additives). 1997. Antimicrobial Feed Additives. Ministry of Agriculture, Stockholm.

Carpet, D. E. 1996. Microbiological hazards for humans of antimicrobial growth promoter use in animal production. Rev. Med. Vet. 147: 851-862.

Danish Veterinary Laboratory Manual. 1995. The effect of avoparcin used as a feed additive on the occurrence of vancomycin resistant Enterococcus faecium in pig and poultry production, July.

Demir, Şenay Sarica, E., Özcan, M. A. and Suiçmez, M. 2008. The use of natural feed additives as alternative to an antibiotic growth promoter in broiler diets. European Poult. Sci., Vol. 72.

Duffy, G., Cloak, 0. M., O'Sullivan, M. G., Guillet, A., Sheridan, J. J., Blair, I. S. and McDowell, D. A. 1999. The incidences and antibiotic resistance profiles of Salmonella spp on Irish retail meat products. Food Microbial. 16: 623-631.

Fey, P. D., Safranek, T. J., Rupp, M. E., Dunne, E. F., Ribot, E., Iwen, P. C., Bradfors, P. A., Angulo, F. J. and Hinrichs, S. H. 2000. Ceftriaxone-resistant Salmonella infection acquired by a child from cattle. New Engl. J. Med. 342: 1242-1249.

Fone, D. L. and Barker, R. M. 1994. Association between human and faun animal infections with Salmonella typhimurium DT104 in cattle in Herefordshire. Comm. Dis. Rep. 4: R136-140.

Glynn, K. M., Bopp, C., Dewitt, W., Dabney, P., Moklitar, M. and Angulo, F. 1998. Emergence of multidrug-resistant Salmonella enterica serotype Typhimurium DT104 infections in the United States. New Engl. J. Med. 338: 1333-1338.

Gold, H. S. and Moellering, R. C. 1996. Antimicrobial-drug resistance. New Engl. J. Med. 335: 1445-1453.

Green, A. A. and Sainsbury, D. W. B. 2001. The role of probiotic in producing quality poultry products. XV European Symposium on the quality of poultry meat. pp. 245-251.

Gustafson, R. H. and Bowen, R. E. 1997. Antibiotic use in animal agriculture. J. Appl. Bacleriol. 83: 531-5411. 
Bang. J. Anim. Sci. 2009, 38(1\&2)

Hammerum, A. M., Jensen, L. B. and Aarestrup, F. M. 1998. Detection of the satA gene and transferability of virginiamycin resistance in Enterococcus faecium, from farm animals. FEMS Microbial. Lett. 168: 145-151.

Hinton, A. Jr., Buhr, R. J. and Ingram, K. K. 2000. Reduction of Salmonella in the crop of broiler chickens subjected to feed withdrawal. Poult. Sci., 79: 1566-1570.

Hinton, M., Rixson, P. D., Allen, V. and Linton, A. H. 1984. The persistence of drug resistant Escherichia coli strains in the majority faecal flora of calves. J. Hyg. (Camb.) 93: 547-557.

Hunter, J. E., Hart, C. A., Shelley, J. C., Walton, J. R. and Bennett, M. 1993. Human isolates of apramycin-resistant Escherichia coli which contain the genes for the AAC(3)IV enzyme. Epiderniol. Infect. 110: 253-259.

Jacobs-Reitsma. W. F., Kan, C. A. and Bolder, N. NI. 1994. The induction of quinolone resistant Campylobacter bacteria in broilers by quinolone treatment. Lett. Appl. Microbiol. 19: 228-231.

Jensen, L. B., Ahrens, P., Dons, L., Jones, R. N., Hammerum, A. M. and Aarestrup, F. M.1998. Molecular analysis of Tn1546 in Enterococcus faecium isolated from animals and humans. J. Clin. Microbiol. 36: 437-442.

Khachatourians, G. G., 1998. Agricultural use of antibiotics and the evolution and transfer of antibiotic-resistant bacteria. Canadian Medical Association Journal, 159: 1129-1136.

Kuhn, I., Iversen, A., Burman, L. G., Olson-Li1jecluist, B., Franklin, A., Finn, M., F. Aarestrup, F. M., Scyfarih, A. M., Blanch, A. R., Taylor, H., Caplin, J., Moreno, M. A., Dominguez, L. and Molby, R. 2000. Epidemiology and ecology of enterococci, with special reference to antibiotic resistant strain, in animals, humans and the environment. Example of an ongoing project within the European research programme. Int. J. Antimicrob. Agents 14: 337-342.

Lawrence, K. 1997. Growth promoters. In: WHO (1997) The medical impact of the use of antimicrobials in food animals. Report of a WHO Meeting Berlin, Germany, October 1997, EDG general comments.

Linton, A. H., Hedges, A. J. and Bennett, P. M. 1988. Monitoring for the development of antimicrobial resistance during the use of olaquindox as feed additive on commercial pig farms. J. Appl. Bacteriol. 64:311-327.

MAFF. 1998. A review of antimicrobial resistance in the food chain. A Technical Report for the UK Ministry of Agriculture, Food and Fisheries.

Moore, J., Madden, H., Kerr, J. R., Wilson, T. S. and Murphy, P. G.1996. Erythromycin resistant thermophilic Campylobacter species isolated froth pigs. Vet. Rec, 138: 306-307.

Pavia, M., Nobile, C. G., Salpictro, L. and Angelillo, I. F. 2000. Vancomycin resistance and antibiotic susceptibility of enterococci in raw meat. J. Food Prot. 63: 912-925.

Piriz, S., Valle, J., Malcos, E. M., Fuente, Cid, R. de la D., Ruiz-Santaquiteria, J. A. and Vadillo, S. 1996. In vitro activity of fifteen antimicrobial agents against methicillin-resistant and methicillin-susceptible Staphylococcus intermedius. J. Vet. Pharmacol. 19: 118-123 .

Regulation (EC) No. 1831/2003 of the European Parliament and of the council of 22 September (2003). OJ L 268, 29-43, 18.10.2003.

Saenz, Y., Zarazaga, M., Lantern, M., Gastanares, M. J., Bacquero, F. and Torres, C. 2000. Antibiotic resistance in Campylohactcr strains isolated from animals, foods and human in Spain in 1997-1998. Antimicrob. Chemother. 44: 267-271.

Salyers, A. A. and C. F. Amabile-Cuevas. 1997. Why are antibiotic genes so resistant to elimination? Antimicrob. Chemother. 41: 2321-2325. 
Swann, M. M. 1969. Use of antibiotics in animal husbandry and veterinary medicine. UK Joint Committee Report.

Taylor, D. J. 1999. The pros and cons of antimicrobial use in animal husbandry. Bailliere's Clin. Infect. Dis. 5: 269-287.

Thompson, J. L. and Hinton, M. 1997. Antibacterial activity of formic and propionic acids in the diet of hens on salmonellas in the crop. Bri. Poult. Sci., 38: 59-65.

Threlfall, E. J., L. R. Ward, J. A. Frost and G. A. Willshaw. 2000. Spread of resistance from food animals to man- the UK experience. Acta Vet. Scand. Suppl. 93: 63-68.

van den Bogaard, A. E, L. Jensen and E. E. Stobberingh. 1997. Vancomycin-resistant enterococci in turkeys and farmers. New Engl, J. Med. 337: 1558-1559.

van den Bogaard, A. E. and Stobberingh, E. E. 1999. Antibiotic usage in animals. Drugs 58: 589-607.

van den Bogaard, A. E. and Stobberingh, E. E. 2000. Epidemiology of resistance to antibiotics. Links between animals and humans, Int. J. Antimicrob. Agents 14: 327-35.

Wall, P. G, Morgan, D., Lainclen, K., Griffin, M., Threlfall, E. J., Ward, R. and Rowe, B. 1995. Transmission of multi-resistant strains of Salmonella typhimurium from cattle to man. Vet. Rec. 136: 591-592.

Watts, J. L., Yancey, R. J., Salmon, S. A. and Case, C. A. 1994. A 4-year survey of antimicrobial susceptibility trends for isolates from cattle with bovine respiratory disease in North America. J. Clin Microbiol. 32: 725-731.

WHO (World Health Organization), 1998. The use of quinolones in food animals and potential impact on human health. Report of a WHO meeting Geneva, Switzerland, June 1998.

Williams Smith, H. 1980, Antibiotic-resistant Escherichia coli in market pigs in 1956-1979: the emergence of organisms with plasmid-borne trimethoprim resistance. J. Hyg. (Lond.) 84: 467-477.

Woodford, N. 1998. Glycopeptide-resistant Enterococci: a decade of experience. J. Med. Microbiol. 47: 849-862.

Wray, C., Hedges, R., Shannon, K. P. and Bradley, D. E. 1986. Apramycin and gentamicin resistance in Escherichia coli and Salmonella isolated from farm animals. J. Hyg. (Lond) 97: 445-456. 